\title{
Humanised $|g G|$ antibody variants targeting membrane-bound carcinoembryonic antigen by antibody-dependent cellular cytotoxicity and phagocytosis
}

\author{
SQ Ashraf',2, P Umana ${ }^{3}$, E Mössner ${ }^{3}$, T Ntouroupi', P Brünker ${ }^{3}$, C Schmidt ${ }^{3}$, JL Wilding' ${ }^{1}$ NJ Mortensen ${ }^{2}$ \\ and WF Bodmer ${ }^{*, 1}$
}

'Cancer and Immunogenetics Laboratory, Department of Medical Oncology, Weatherall Institute of Molecular Medicine, Oxford, UK; ${ }^{2}$ Department of Colorectal Surgery, John Radcliffe Hospital, Headington, Oxford, UK; ${ }^{3}$ Glycart Biotechnology AG, Wagistrasse, Schlieren, Zurich, Switzerland

BACKGROUND: The effect of glycoengineering a membrane specific anti-carcinoembryonic antigen (CEA) (this paper uses the original term CEA for the formally designated CEACAM5) antibody (PRIA3) on its ability to enhance killing of colorectal cancer (CRC) cell lines by human immune effector cells was assessed. In vivo efficacy of the antibody was also tested.

METHODS: The antibody was modified using EBNA cells cotransfected with $\beta$-I,4-N-acetylglucosaminyltransferase III and the humanised hPRIA3 antibody genes.

RESULTS: The resulting alteration of the Fc segment glycosylation pattern enhances the antibody's binding affinity to the Fc $\gamma$ RIIla receptor on human immune effector cells but does not alter the antibody's binding capacity. Antibody-dependent cellular cytotoxicity (ADCC) is inhibited in the presence of anti-FcyRIII blocking antibodies. This glycovariant of hPR I A3 enhances ADCC I0-fold relative to the parent unmodified antibody using either unfractionated peripheral blood mononuclear or natural killer (NK) cells and CEA-positive CRC cells as targets. NK cells are far more potent in eliciting ADCC than either freshly isolated monocytes or granulocytes. Flow cytometry and automated fluorescent microscopy have been used to show that both versions of hPRIA3 can induce antibody-dependent cellular phagocytosis (ADCP) by monocyte-derived macrophages. However, the glycovariant antibody did not mediate enhanced ADCP. This may be explained by the relatively low expression of Fc $\gamma$ RIlla on cultured macrophages. In vivo studies show the efficacy of glycoengineered humanised IgGI PRIA3 in significantly improving survival in a CRC metastatic murine model.

CONCLUSION: The greatly enhanced in vitro ADCC activity of the glycoengineered version of hPRIA3 is likely to be clinically beneficial. British Journal of Cancer (2009) I I , 1758- 1768. doi: I0.1038/sj.bjc.6605355 www.bjcancer.com

(c) 2009 Cancer Research UK

Keywords: PRIA3; CEA; ADCC; ADCP; colorectal cancer; glycoengineering; NK cells; monocyte-derived macrophages

Antibodies are increasingly used for immunotherapy of cancers, with over 200 currently in trials and 12 licensed for use in treatment (Adams and Weiner, 2005; Carter, 2006; Reichert and Valge-Archer, 2007). There are now three antibodies approved by the US FDA for treatment of advanced colorectal cancer (CRC) (Goldberg, 2005; Saltz et al, 2006; Reichert and Valge-Archer, 2007). The main potential advantages of this form of therapy lie in their specificity, lesser side-effects and their ability to elicit a tumour response by multiple mechanisms (Carter, 2006; Reichert and Valge-Archer, 2007). The outcomes of early clinical trials using murine unconjugated and radioconjugated monoclonal antibodies for cancer treatment were disappointing (Goldenberg, 2002; Reichert and Valge-Archer, 2007) probably because of

* Correspondence: Professor WF Bodmer, Cancer and Immunogenetics Laboratory, Weatherall Institute of Molecular Medicine, Oxford, UK; E-mail: walter.bodmer@hertford.ox.ac.uk

Received I8 May 2009; revised 2 September 2009; accepted II September 2009 immune responses to foreign proteins reducing serum half-lives, and the delivery of inadequate radiation doses from the radioconjugates to the tumour (Goldenberg, 2002; Sharkey and Goldenberg, 2005; Reichert and Valge-Archer, 2007). Responses were also severely limited by the attenuated ability of the $\mathrm{Fc}$ segment of murine antibodies to interact with the relevant receptors of the human immune system. These problems have now been largely overcome by the development of technologies for the production of chimeric, humanised and completely human antibodies (Clynes, 2006).

Two lines of evidence support the importance of immune function for naked antibody therapy. Firstly, Clynes et al (2000) showed that antibody-based killing of xenografted and syngeneic tumours was abrogated in $\mathrm{Fc} \gamma \mathrm{R}$ knockout mice. This established that the ability of antibodies to reduce tumour burden was greatly reduced in the absence of immune cells expressing Fc $\gamma$ Rs. Secondly, colorectal, lymphoma and breast cancer patients carrying the polymorphic variants in the Fc $\gamma$ RIIIa and Fc $\gamma$ RIIa genes that encode for high affinity binding receptors for the $\mathrm{Fc}$ antibody segments, have the best clinical outcomes following 
antibody treatment (Weng and Levy, 2003; Zhang et al, 2007; Musolino et al, 2008).

Responses to antibody therapy for solid cancers are so far modest for cetuximab and trastuzumab monotherapy. Although cetuximab in combination with irinotecan improves the response rate from $10 \%$ to over $20 \%$ (Cunningham et al, 2004), monotherapy response rates in haematological malignancies are markedly higher than for solid cancers (McLaughlin et al, 1998). This may be due to the increased surface area of haematological tumours that is exposed to antibody binding and to $\mathrm{NK}$ cells (Olszewski and Grossbard, 2004). Emphasis is now being placed on techniques that 'tune' antibodies to make them more efficient at harnessing the immune system for killing solid cancers. Thus, technologies have been developed that engineer Fc antibody segments to enhance their ability to elicit immune effector functions, such as antibody-dependent cellular cytotoxicity (ADCC). One approach uses protein engineering to modify the Fc segment (Lazar et al, 2006). Another uses glycoform engineering, which has been shown to improve in vitro ADCC by 10-100-fold (Umana et al, 1999; Niwa et al, 2004b; Schuster et al, 2005). In this study, we have used glycoengineering to enhance the immune effector function of an antibody that we have shown earlier to kill CRC-derived cell lines by ADCC (Conaghan et al, 2008).

The antibodies now used for the treatment of CRC target EGFR and VEGF (Cunningham et al, 2004; Adams and Weiner, 2005; Goldberg, 2005; Carter, 2006; Saltz et al, 2006) and only appear to be effective in subsets of patients. Earlier work from our laboratory has shown that the antibody PR1A3, which is specific for membrane-bound carcinoembryonic antigen (CEA, formally designated CEACAM5), elicits ADCC against CEA-positive CRC cell lines even in the presence of super-physiological levels of free CEA (Durbin and Bodmer, 1987; Durbin et al, 1994; Conaghan et al, 2008). CEA is present on a high proportion of colorectal cancers, in which it is accessible to intravenously administered antibody, whereas in normal colorectal epithelium, due to the apical localisation of the antigen, it is not (Granowska, 1993). Radioconjugates targeting CEA have been used in early phase clinical trials in CRC (Wong et al, 2004; Liersch et al, 2005), but there is so far no unconjugated anti-CEA antibody licensed for treatment (Blumenthal et al, 2008). The pre-clinical studies reported here are directed at optimising PR1A3 for use in the treatment of colorectal cancer. This antibody has been shown to bind specifically to CEA in the B3-GPI domains. This epitope is at the point CEA anchors into the membrane, and this presumably explains why PR1A3 binds to membrane-bound CEA but not soluble CEA (Durbin et al, 1994; Conaghan et al, 2008).

The three classes of $\mathrm{Fc} \gamma$ Rs are expressed on NK cells, known to be potent activators of ADCC (Schmitz et al, 2002; Lazar et al, 2006; Conaghan et al, 2008), and on monocytes and granulocytes, which have also been identified as having at least some potential for antibody-dependent killing of target cells, for example, by antibody-dependent cellular phagocytosis (ADCP) (Munn et al, 1991; Huls et al, 1999; Dhodapkar et al, 2005; Lazar et al, 2006; Karagiannis et al, 2007; McEarchern et al, 2007). We describe here a modified phagocytosis assay, based on that developed by Munn et al (1991), and its application to the in vitro testing of the ability of humanised and glycoengineered PR1A3 to kill CRC-derived cell lines. We also present in vivo data that shows the efficacy of PR1A3 as a therapeutic agent in a mouse xenograft model.

\section{MATERIALS AND METHODS}

\section{Cell lines}

The SKCO-1 (from ATCC), LS174T (from BH Tom, NW University, Chicago), LoVo (from ATCC), HCT116 (from ATCC) and MKN45 (from Cell Services LIF, CRUK, London, UK) cell lines were cultured as described (Conaghan et al, 2008). For cytotoxicity and phagocytosis assays, cells were suspended in 2\% RPMI 1640 medium with $1 \%$ glutamine and $10 \%$ FCS (RPMI complete medium).

\section{Antibodies}

PR1A3 The original murine IgG1 $\kappa$ monoclonal antibody to CEA (Richman and Bodmer, 1987) was humanized by Stewart et al (1999). Murine (mPR1A3, IgG1) and unmodified humanized (uhPR1A3, IgG1) antibodies were acquired from the Biotherapeutics Development Unit, Clare Hall, CRUK, London, UK. Murine IgG2a PR1A3 (mPR1A3, IgG2a) and a glycoengineered version of re-derived humanised IgG1 PR1A3 (ghPRA1A3, IgG1) were made by joining the variable region of PR1A 3 to murine IgG2a and the complementarity determining regions of PR1A3 to human IgG1 variable regions, respectively (Jones et al, 1986). Glycoengineering was as described (Umana et al, 1999; Schuster et al, 2005). Briefly, vectors containing IgG heavy and light chains, and $\beta(1,4)-N$ acetylglucosaminyltransferase-III (GnT-III), were transfected into EBNA cells. The enzyme modifies the $\mathrm{N}$-glycosylation pattern at Asn-297 of the IgG heavy chain resulting in a high degree of bisected, afucosylated oligosaccharides (Umana et al, 1999; Schuster et al, 2005; Ferrara et al, 2006), which has been shown earlier to increase the affinity to Fc $\gamma$ RIIIa (Ferrara et al, 2006). The modified antibody was purified from culture supernatants using Protein-A, cation-exchange chromatography and subsequent size-exclusion chromatography.

SM3E This is a humanised IgG1 antibody that binds with extremely high affinity $\left(K_{\mathrm{d}}=20 \mathrm{pM}\right)$ to both soluble and membrane-bound CEA (Graff et al, 2004). A glycoengineered variant was generated using the methods described above.

Blocking antibodies Purified IgG1 anti-CD16 (Fc $\gamma$ III) (clone 3G8, which is unable to distinguish between Fc $\gamma$ RIIIa and Fc $\gamma$ RIIIb), purified IgG1 anti-CD64 (clone 10.1), and $\mathrm{Fab}_{2}$ fragments targeting CD16 (clone 3G8), CD32 (Fc $\gamma$ II, clone 7.3) and CD64 (Fc $\gamma$ II, clone 10.1) were purchased from Ancell Corp, Bayport, MN, USA. Purified IgG2b anti-CD32 (clone IV.3) was purchased from Stemcell Technologies (Vancouver, Canada).

FITC-conjugated murine anti-human IgG (clone G18-145), CD3-FITC, CD11b-PE, CD14-PE, CD15-FITC, CD16-PE, CD19-PE, CD32-PE, CD45-PE, CD56-APC, CD64-FITC, IgG1-FITC (isotype control), IgG1-PE (isotype control) and IgG1-APC (isotype control) were obtained from BD Biosciences, Oxford, UK. AntiHLA class II (DA-2) was obtained from Monoclonal Antibody Services, CRUK (Brodsky et al, 1979).

\section{Isolation of immune effector cells}

Peripheral blood mononuclear cells (PBMCs) were isolated from healthy laboratory volunteers, having taken informed consent, or from buffy coats obtained from single donors (National Blood Service, Bristol, UK). The Rosettesep Human NK isolation cocktail (Stemcell Technologies) was used to obtain an enriched population of human NK cells from blood, as described (Roda et al, 2006). Granulocytes were separated using One-step Polymorph (Accurate Chemical and Scientific Corp, Westbury, NY, USA). Monocytes were enriched from blood using the Rosettesep Human Monocyte Enrichment Cocktail (Stemcell Technologies). Purification was verified by phenotypic analysis of surface markers (See Supplementary Materials for details).

\section{Flow cytometric analysis to compare uhPR1A3 and ghPR1A3 binding to membrane-bound CEA}

Cells from SKCO-1, a high CEA expressing CRC line used as target, were incubated in varying concentrations of uhPR1A3 or ghPR1A3 
$\left(0.001-100 \mu \mathrm{g} \mathrm{ml}^{-1}\right)$, and with anti-human IgG-FITC as secondary antibody. The cells were then washed once with FACS buffer (PBSA, 1\% FCS, 1\% Sodium Azide) and the supernatant removed before resuspending in $2 \%$ paraformaldehyde in PBSA. FACS analysis was carried out using a FACS Calibur Flow cytometer.

\section{Fluorescence-based EuTDA cytotoxicity assay}

As described (Conaghan et al, 2008), a fluorescent probe, BATDA (Blomberg et al, 1996) (Perkin Elmer, Boston, MA, USA), was used to label target cells. PBMCs, NK cells, monocytes and granulocytes were used as effectors with varying effector: target cell ratios and concentrations of antibodies. After appropriate incubation, supernatant was added to Europium in 96-well plates and the resulting fluorescence read in a time-resolved fluorometer.

The EuTDA assay was used to compare the ADCC activity of mPRA13 IgG1, mPR1A3 IgG2a and uhPR1A3 IgG1 on SKCO-1 cells, using antibody at a final concentration of $20 \mu \mathrm{g} \mathrm{ml}^{-1}$ and either PBMCs or NK cells as effectors.

The effect of blocking Fc $\gamma$ Rs I, II and III using $\mathrm{Fab}_{2}$ or IgG antibodies was assessed using the EuTDA to measure uhPR1A3 mediated ADCC of SKCO-1. PBMC and enriched NK cells were used as effectors. Murine IgG prostate membrane specific antigen (PMSA, provided by Robert Vessella, University of Washington) was used as an isotype murine control.

The relative ability of PBMCs, NK cells, monocytes and granulocytes, enriched, as described earlier, to elicit ADCC was assessed using the EuTDA assay with uhPR1A3.

\section{Monocyte-derived macrophages for phagocytosis assays}

Enriched monocytes were cultured on Lumox Petraperm Plates (Greiner, Bio-One, North America, Monroe, NC, USA), for 8-12 days at $37^{\circ}$ in a $5 \% \mathrm{CO}_{2}$ incubator, in X-VIVO 15 medium (BioWhittaker, Walkersville, MD, USA), supplemented with M-CSF, GM-CSF and $\gamma$ IFN (Peprotech, UK) (see Supplementary Materials for details). Target cells (SKCO-1) were labelled with CellTracker Green CMFDA (Invitrogen, San Diego, CA, USA). Free label was washed off before incubation with varying concentrations of uhPR1A3 or ghPR1A3 $\left(0.1-10 \mu \mathrm{g} \mathrm{ml}^{-1}\right)$. Effector monocyte-derived macrophages were added ( $3: 1-8: 1$ effector : target ratio), the cells were incubated for $1 \mathrm{~h}$ at $37^{\circ}$ and analysed using FACS Calibur to measure ADCP.

An alternative ADCP assay was developed using an automated microscope (Ikoniscope, Ikonisys, New Haven, CT, USA) (Ntouroupi et al, 2008). Target cells and macrophages, stained as described above, were deposited on to a poly-l-lysine coated slide, fixed with $2 \%$ formaldehyde. The slides were washed with PBS containing Tween (PBS-Tween), covered with blocking solution and Goat anti-mouse-HRP (1:100 dilution in blocking solution) added as a secondary antibody. The slides were washed with PBS-Tween, before adding Tyramide-647 (1:100 dilution).

Phagocytosis events were detected using the Ikoniscope imaging system (Ntouroupi et al, 2008). Slides are first scanned at low magnification $(\times 10)$ to detect green label and then revisited at high magnification $(\times 100)$ to identify red labelled macrophages with 'engulfed' green targets.

\section{In vivo testing of $\mathrm{PR} 1 \mathrm{~A} 3$}

Six to 12-week-old SCID/Beige mice were used for animal experiments. All experiments were performed after ethical approval from the Swiss Veterinary Office. LS174T cells were maintained in DMEM medium with $1 \%$ glutamine and $10 \%$ FCS (E4 complete medium). A murine model for CRC tumours was set up by intra-splenic injection of LS174T $\left(3 \times 10^{6}\right.$ cells per mouse) under aseptic conditions (day 0 ). This resulted in the development of liver metastasis. Passive antibody protection was measured by comparing the survival of mice $(n=10$ for each group) after intravenous injection of either glycoengineered humanised IgG1 PR1A3, or glycoengineered high affinity IgG1 anti-CEA antibody (clone SM3E,) or vehicle PBS control. The SM3E antibody, unlike PR1A3, is not membrane CEA specific. Antibody injections were performed at days 7,14 and 21 with a treatment dose of $25 \mathrm{mg} \mathrm{kg}^{-1}$ of bodyweight of mouse. Termination criteria were in accordance with the Swiss Veterinary Office.

\section{ADCC and ADCP data analysis}

Percentage cell lysis in the cytotoxicity assays was calculated as [experimental release-background release]/[maximum release-background release $\times 100$. Antibody-dependent (specific) lysis was calculated as [experimental release-antibody-independent release]/[maximum release-antibody-independent release] $\times 100$. The standard error of the mean of multiple experiments was calculated using Graphpad Prism software, San Diego, CA, USA. Percentage cell phagocytosis was calculated using the formula: number of dual-stain positive target cells (cells engulfed by macrophages) divided by the total number of target cells. Standard normal distribution tests were performed to test the significance of differences found.

\section{RESULTS}

The binding of uhPR1A3 and ghPR1A3 to SKCO-1, based on FACS analysis, was similar over a wide range of concentrations $(0.001-$ $100 \mu \mathrm{g} \mathrm{ml}^{-1}$ ) (Figure 1; see Supplementary Figure S1). Glycoengineering the Fc segment of PR1A3 has, therefore, no effect on the binding efficiency of the antibody to its epitope on a CEAexpressing CRC line. The affinity of PR1A3 Fab for cell-bound CEA is approximately $10 \mathrm{~nm}$.

The ADCC mediated activities of mPR1A3IgG1, mPR1A3IgG2a and uhPR1A3IgG1, using human effector cells and SKCO-1 as targets, are illustrated in Figure $2 \mathrm{~A}$ and $\mathrm{B}$. The data show that uhPR1A3IgG1 kills much more actively than either mPR1A3IgG1 or mPR1A3IgG2a. PR1A3 does not mediate any killing in the absence of immune cells (data not shown). These data confirm that hPR1A3 mediated killing depends on the appropriate $\mathrm{Fc}-\mathrm{Fc} \gamma \mathrm{R}$ interaction.

Using enriched NK cells as effectors and SKCO-1 as targets, the effects on hPR1A3 mediated ADCC of blocking with $\mathrm{Fab}_{2}$ and IgG antibodies against the three known human classes of Fc $\gamma$ Rs, CD64 $(\mathrm{Fc} \gamma \mathrm{RI}), \mathrm{CD} 32(\mathrm{Fc} \gamma \mathrm{RII})$ and $\mathrm{CD} 16$ (Fc $\gamma \mathrm{RIII})$, are shown in Figure 3. CD16 $\mathrm{Fab}_{2}$ blocks the ADCC somewhat more than CD16 IgG, whereas CD32 $\mathrm{Fab}_{2}$ had no significant effect. However, CD32 IgG

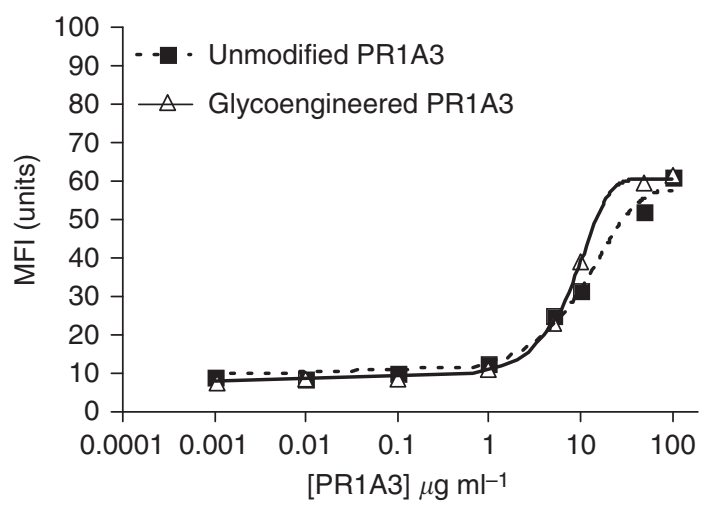

Figure I Comparison of the binding of unmodified humanised $|\mathrm{g} G|$ PRIA3 (uhPRIA3) and glycoengineered IgGI PRIA3 (ghPRIA3) to the high CEA expressing cell line SKCO-I. Mean fluorescent intensities, based on flow cytometric analysis, of uhPRIA3 and ghPRI A3 at different antibody concentrations. Sigmoidal dose-response curves are fitted using Prism Graphpad software (goodness of fit, $R^{2}>0.98$ ). 
A
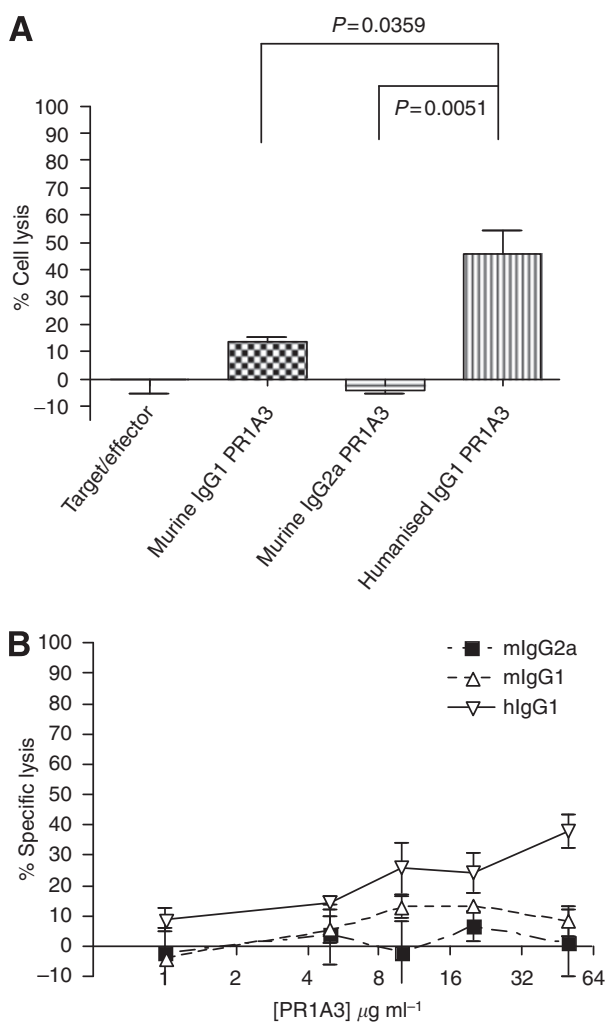

Figure 2 (A) Comparison of the ADCC activity of PRIA3 antibodies with differing Fc portions (murine $\operatorname{lgG}$, murine $\lg \mathrm{G} 2 \mathrm{a}$ and humanised $\mid g G I)$. PBMC were used as effectors and SKCO-I used as the target ( 100 : I effector: target ratio). Antibodies were used at a final concentration of $10 \mu \mathrm{g} \mathrm{ml}^{-1}$. The control was targets and effectors with no antibody. The $P$-values are for the significance of the differences between controls and the hlgGIPRIA3 results, based on t-tests. (B) Comparison of the ADCC activity of PRIA3 antibodies with differing Fc portions (murine $|g G|$, murine $\lg \mathrm{G} 2 \mathrm{a}$ and humanised $\lg \mathrm{Gl}$ ) over a range of antibody concentrations from I to $50 \mu \mathrm{gml}^{-1}$. PBMC were used as effectors and SKCO-I as target (50: I, effector: target ratio)

(clone IV.3) was as effective, if not more so, than CD16 IgG in inhibiting both ADCC and antibody-independent killing. Neither CD64 $\mathrm{Fab}_{2}$ nor IgG had any significant effect, whereas PMSA antibody, used as a non-specific blocking control, showed the absence of non-specific competition for Fc $\gamma$ Rs on effector cells.

NK cells, which predominantly express Fc $\gamma$ RIIIa, mediate ADCC at much lower effector: target ratios than whole PBMC (Schmitz et al, 2002; Lazar et al, 2006; Conaghan et al, 2008). Monocytes, however, express all three classes of $F c \gamma$ Rs on their surface, and granulocytes express both Fc $\gamma$ RIIa and IIIb. Thus, both these cells types might be expected to contribute to ADCC. NK cells, monocytes and granulocytes were therefore compared as effectors for ADCC using the EuTDA assay, as shown in Figure 4. NK cells, defined as CD3-/CD56 + /CD16 + , using CD56 ( $x$-axis) and CD16 $(y$-axis) antibodies (Figure 4A; left panel before, and right panel after sorting) elicited significant ADCC with $20 \mu \mathrm{g} \mathrm{ml}^{-1}$ of uhPRA1A3 IgG1 and SKCO-1 as targets even at effector to target ratios of 10:1 (Figure 4B). Neither, monocytes, defined as CD3 $-/ C D 11 b+/ C D 14+/ C D 15-/ C D 16 l o w / C D 19-/ C D 32+/ C D 45+/$ CD56-/CD64 + (Figure 4C; left panel before, and right panel after sorting using anti CD14 ( $x$-axis, stain intensity; $y$-axis, event frequency), nor granulocytes, defined as CD3-/CD14-/CD15 + I CD16 + /CD19-/CD56- (Figure 4E after enrichment using antiCD15) showed any evidence of ADCC even at effector : target ratios of up to $40: 1$ (Figure $4 \mathrm{D}$ and F).

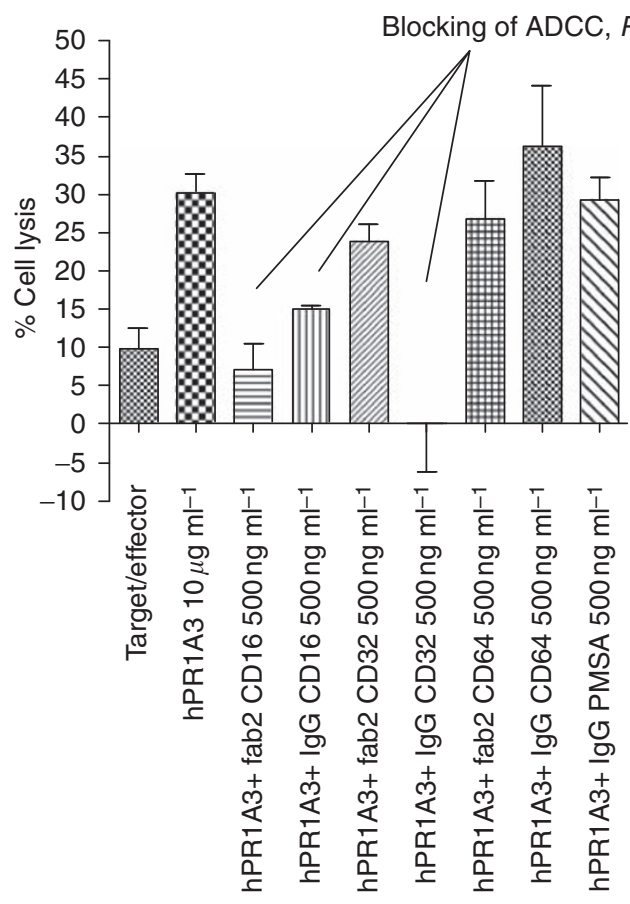

Effector:target ratio $=8: 1$

Figure 3 Effect of FcyR blocking on unmodified humanised PRIA3induced ADCC, using anti-CDI6, 32 and $64 \mathrm{Fab}_{2}$ or IgG. SKCO-I was used as the target and NK cells as the effectors (effector:target ratio $=8: 1)$. The $P$-values are for the significance of the differences between the result using hlgGIPRIA3 and no blocking antibody, based on t-tests.

Figure 5A shows that glycoengineered antibody, ghPR1A3, elicits ADCC at much lower concentrations than the unmodified form. Thus, just $1 \mu \mathrm{g} \mathrm{ml}^{-1}$ of ghPR1A3 kills over $40 \%$ of SKCO-1 target cells, using unfractionated PBMC as effectors, whereas $1 \mu \mathrm{g} \mathrm{ml}^{-1}$ of uhPR1A3 kills only about $10 \%$ of the targets, suggesting 10-100-fold increased effectiveness of the glycoengineered antibody. Figure 5B shows that $1 \mu \mathrm{g} \mathrm{ml}^{-1}$ of ghPR1A3 is significantly more effective at mediating killing than is $1 \mu \mathrm{g} \mathrm{ml}^{-1}$ uhPR1A3 over a range of effector to target ratios from $25: 1$ to $100: 1$, again using PBMC as effectors. Figure 5C shows that the difference between the killing efficiency of ghPR1A3 and uhPR1A3 is similar using effector cells from three different PBMC donors whereas Figure 5D shows that using enriched human NK cells as effectors, ghPR1A3 is significantly more effective than uhPR1A3 at killing SKCO-1 cells over a range of concentrations $\left(1-20 \mu \mathrm{g} \mathrm{ml}^{-1}\right)$, as expected if $\mathrm{NK}$ cells are the main cell type mediating ADCC in PBMC. Figure 5E and F shows that ghPR1A3 was also significantly more effective than uhPR1A3 in killing the intermediate CEA-expressing cancer cell lines MKN45, and, particularly, LoVo, the latter even at an effector:target ratio of $25: 1$. As expected, no enhancement was seen for HCT116, a cell line that does not express CEA (data not shown).

To investigate macrophage-based ADCP (Munn et al, 1991; Watanabe et al, 1999; Lazar et al, 2006; McEarchern et al, 2007), monocytes were cultured to give rise to macrophages, which by FACS analysis were shown to be negative for CD3, CD15, CD19 and CD56, positive for CD11b, CD14, CD32, CD64 and HLA class II and weakly positive for CD16 (see Supplementary Figure S2a). The cultured monocytes adhere to the bottom of the plates and have an enlarged granular appearance, as expected for macrophages (see Supplementary Figure S2b). Freshly harvested macrophages were incubated with green CMFDA labelled SKCO-1, and a range 
of antibody concentrations using macrophage: target ratios from $3: 1$ to $8: 1$. A representative FACS analysis of the mixture of macrophages and target SKCO-1 cells after $1-\mathrm{h}$ at $37^{\circ}$ in the presence of an isotype control (PMSA), uhPR1A3 and ghPR1A3 antibodies $\left(5.0 \mu \mathrm{g} \mathrm{ml}^{-1}\right)$ is shown in Figure 6A. The green-labelled target cells are in the right lower quadrant and the effectors,
A

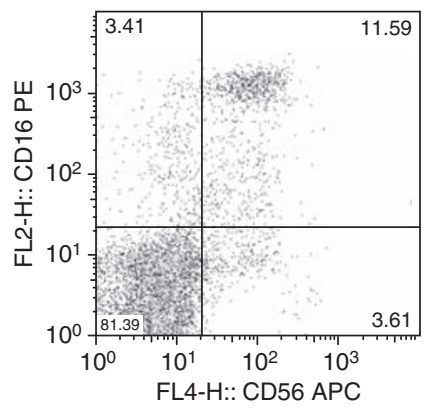

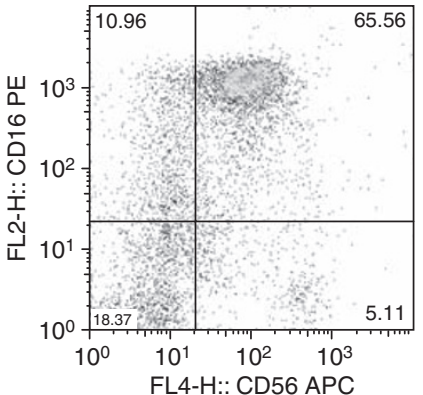

FL4-H:: CD56 APC
C
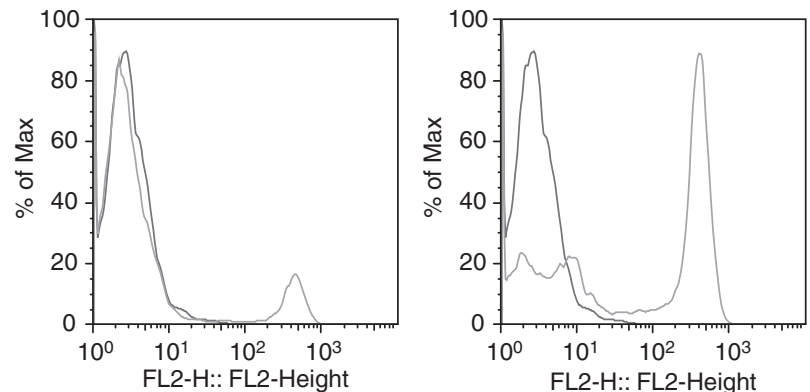
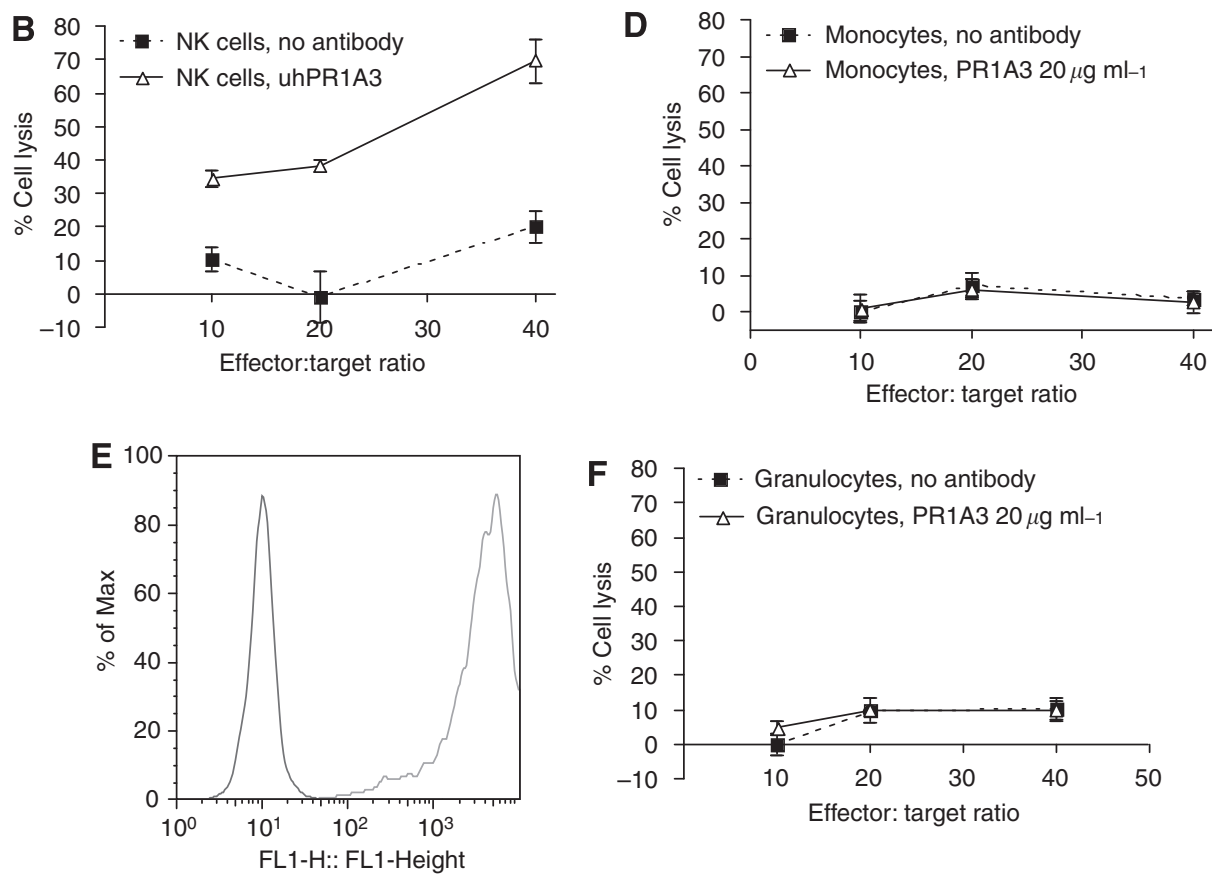

Figure 4 Comparative ADCC activity of different cell types from a single healthy donor. (A) FACS analysis dot plot showing the enrichment of NK cells from PBMC (x-axis, CD56; $y$-axis, CDI6) pre (left-hand dot pot) and post (right-hand dot plot) sorting. (B) NK ADCC activity. Graph of NK ADCC activity against SKCO-I in the absence and presence of $\left.20 \mu \mathrm{g} \mathrm{m}\right|^{-1}$ of hPRIA3 at different effector:target ratios ( $x$-axis) vs \% cell lysis ( $y$-axis). (C) FACS analysis plot showing the enrichment of monocytes from PBMC (x-axis, CDI 4 intensity; $y$-axis, number of events)- pre (left-hand histogram plot) and post (righthand histogram plot) sorting. Grey line presents staining using CDI4 antibody-PE; dark line represents staining with isotype antibody control-PE. (D) Monocyte ADCC activity. Graph of monocyte ADCC activity against SKCO-I, in the absence and presence of $20 \mu \mathrm{gml} \mathrm{m}^{-1}$ of $\mathrm{hPRIA3}$, at different effector: target ratios ( $x$-axis) vs \% cell lysis ( $y$-axis). (E) FACS analysis plot showing the enrichment of granulocytes from fresh blood after sorting ( $x$-axis, CDI5 intensity; $y$-axis, frequency of events). Grey line presents staining using CDI5 antibody-FITC; dark line represents staining with isotype antibody control-FITC. (F) Granulocyte ADCC activity. Graph of granulocyte ADCC activity against SKCO-I in the absence and presence of $20 \mu \mathrm{g} \mathrm{mI}{ }^{-1}$ of hPRIA3, at different effector: target ratios ( $x$-axis) vs \% cell lysis ( $y$-axis).

Figure 5 (A) Comparison of ADCC activity of glycoform engineered humanised PR IA3 (ghPR IA3) with unmodified humanised PR I A3 (uhPR IA3) using PBMC. SKCO-I were used as targets. Effector: target ratio used was 50: I ( $x$-axis, concentration of PRIA3 used; $y$-axis, \% specific lysis). (B) Comparison of

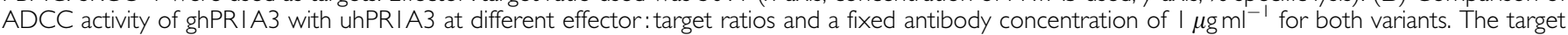
cells were SKCO-I and effectors PBMCs from fresh blood ( $x$-axis, effector: target ratio used; $y$-axis, \% specific lysis). (C) Comparison of ADCC activity of ghPRIA3 with uhPRIA3, using PBMC from three separate donors. SKCO-I (a high CEA expressing cell line) were the targets. Effector:target ratio was 50: I ( $x$-axis, concentration of PRIA3 used; $y$-axis, \% specific lysis). (D) Comparison of ADCC activity of ghPRIA3 with uhPRIA3 using human NK cells and SKCO-I as targets ( $x$-axis, concentration of PRIA3 used; $y$-axis, \% specific lysis). Effector: target ratio used was I0: I. (E) Comparison of ADCC activity of ghPRIA3 with uhPRIA3, using PBMC as effectors, on MKN45 (an intermediate CEA expressing cell line) as the targets. Effector: target ratio was 50: I ( $x$-axis, log concentration of PRIA3 used; $y$-axis, \% specific lysis). (F) Comparison of ADCC activity of ghPRIA3 with uhPRIA3, using PBMC as effectors on LoVo (an intermediate CEA expressing cell line) as the targets. Effector:target ratio was either 25: I or 50: I ( $x$-axis, log concentration of PRIA3 used; $y$-axis, \% specific lysis). 
labelled with PE conjugated anti-CD11b/CD14, in the left upper quadrant of the dot plots. After one hour's culture in the presence of either uhPR1A3 or ghPR1A3 there were substantial numbers of red and green positive signals in the upper right quadrant, presumably representing macrophages containing engulfed target cells, in contrast to the results for the PMSA control (Figure 6A). The proportion of such signals is essentially the same for both uhPR1A3 and ghPR1A3, and is concentration dependent, as shown
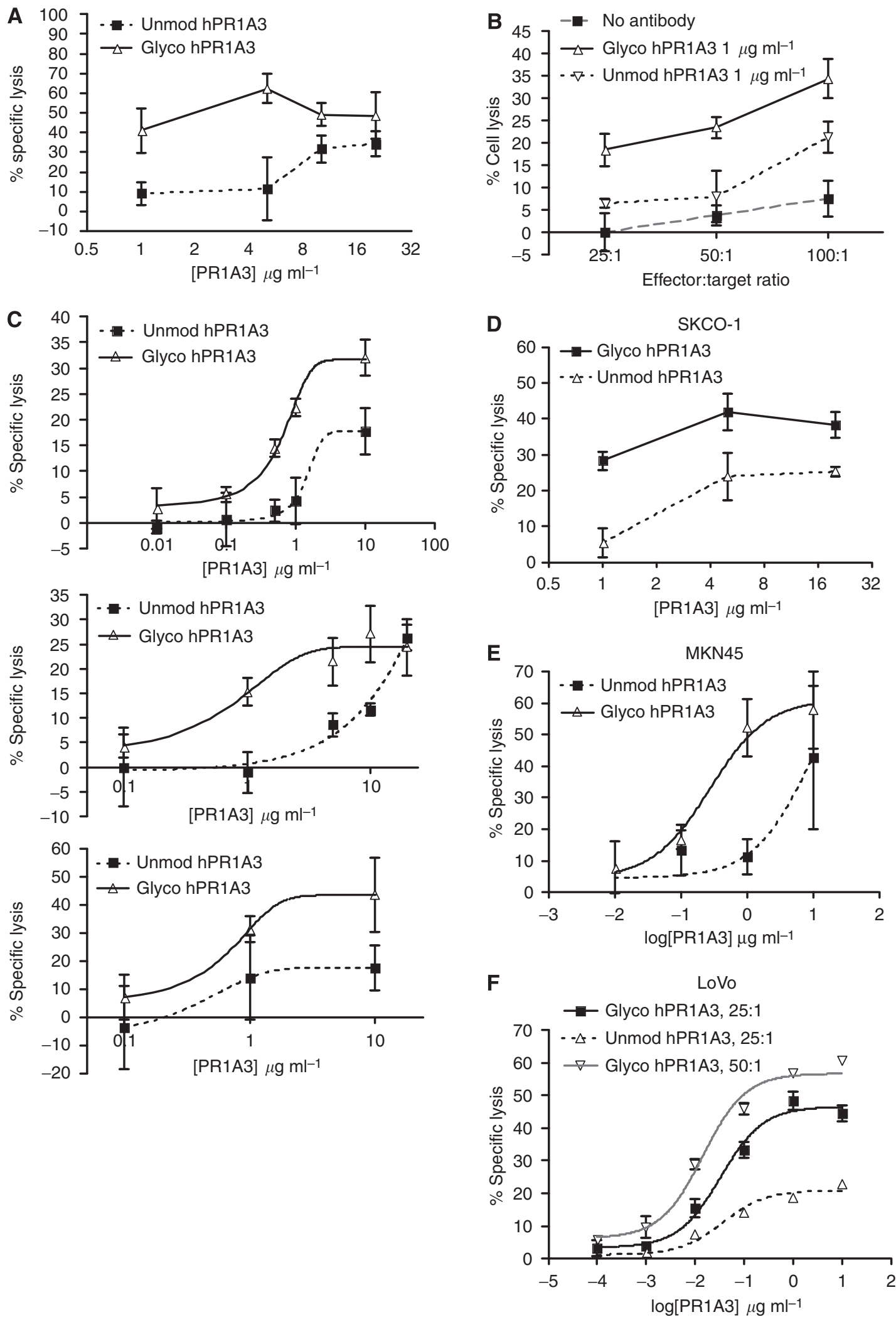
A

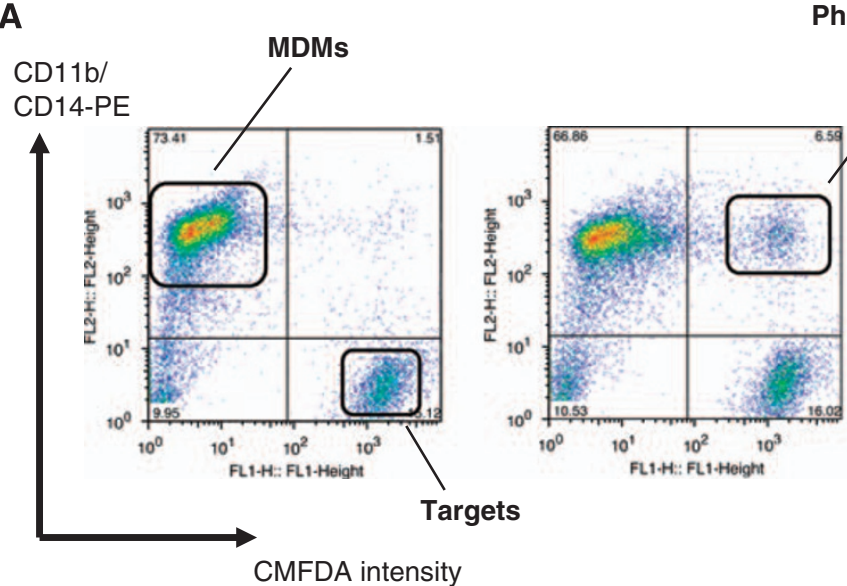

Phagocytosed targets
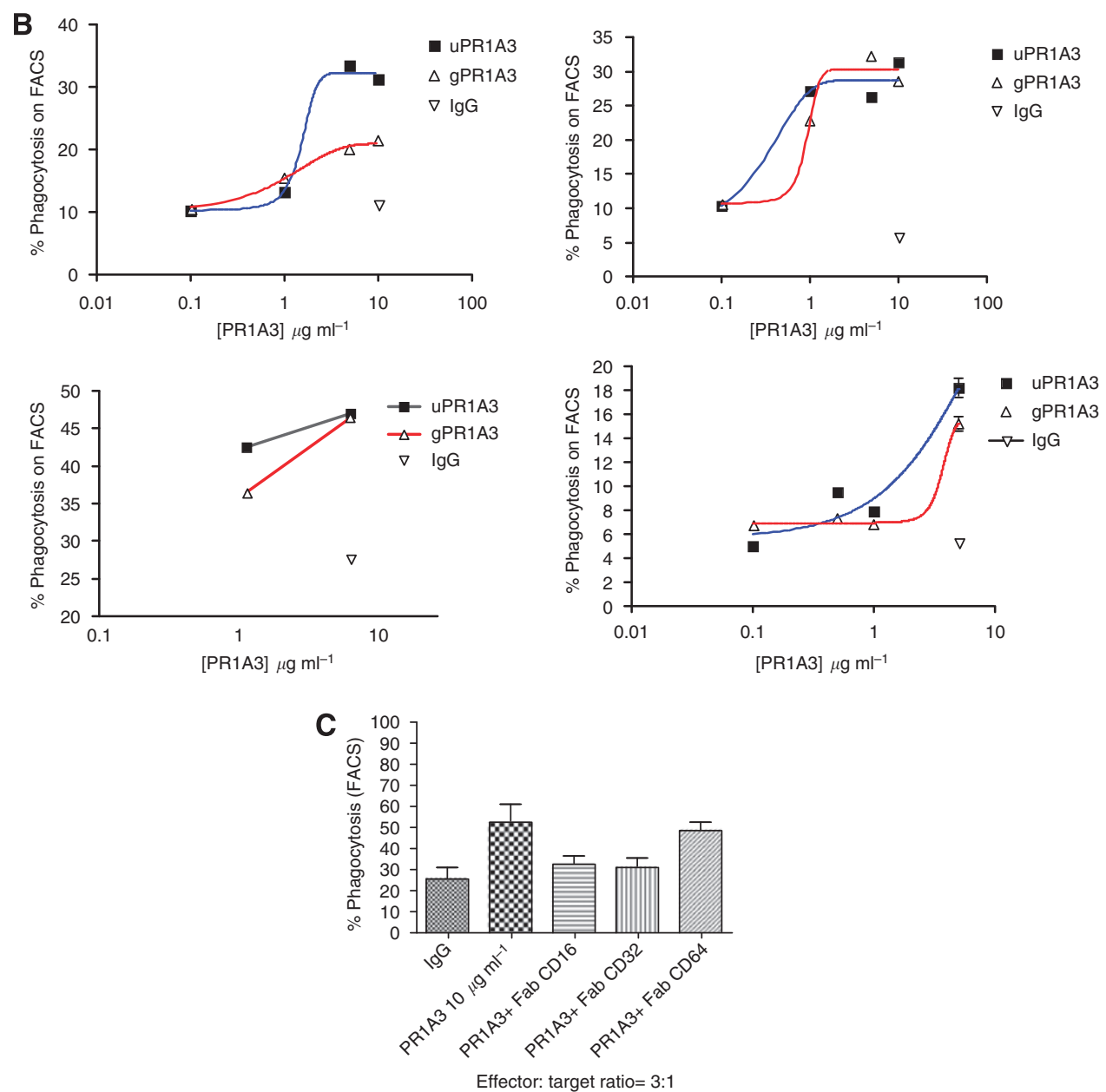

Figure 6 (A) Flow cytometric analysis of ADCP. SKCO-I target cells were stained green with CMFDA and are present in the right lower quadrant of the dot plots. Macrophages were stained with anti-CDI Ib and CD I 4 conjugated with PE. They appear in the left upper quadrant of the dot plots. The left hand dot plot is from a representative I-h culture of macrophages and target cells (SKCO-I) in the presence of IgG isotype control. The middle and right plots are from representative I-h cultures of macrophages and target cells in the presence of uhPRIA3 and ghPRIA3, respectively $\left(5 \mu \mathrm{g} \mathrm{ml}^{-1}\right)$. The effector: target ratio used was 5 : I. (B) Effect of increasing concentrations of uhPRIA3 and ghPRIA3 on phagocytosis. Tumour targets were pre-incubated with an isotype control antibody $\left(\mathrm{lgG},\left.10 \mu \mathrm{gml}\right|^{-1}\right)$ or the variants of hPR IA3 at concentrations of $0.1-10 \mu \mathrm{g} \mathrm{ml} l^{-1}$. ADCP was determined by flow cytometric analysis as the percentage of targets in the upper right hand quadrant (see Figure 6C). The four graphs represent responses from four separate donors. (C) Effect of Fc $\gamma R$ blocking on ADCP. Flow cytometry was used to calculate the percentage of tumour cell engulfment by cultured macrophages in the presence of I $0 \mu \mathrm{g} \mathrm{ml}^{-}$

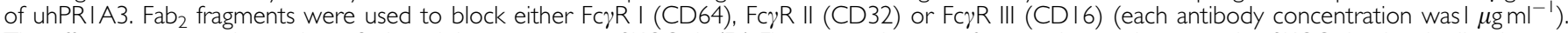
The effector: target ratio used was 3: I, and the targets were SKCO-I. (D) Fluorescent images of macrophages phagocytosing SKCO-I using the Ikoniscope. The macrophages (red) have been stained with anti-CDI4 and anti-CDI Ib primary antibodies followed by goat anti-mouse-HRP and Tyramide 647. The target cell line (SKCO-I) was stained green with CMFDA (Celltracker probe). The left hand panels show microscope composite images viewed with FITC (green), Cy5 (for tyramide 647) and DAPI (blue) channels. The second, third and fourth panel column show the same cells viewed separately with the DAPI, green and Cy5 channels. Each represents a different phagocytic event. 
D Composite
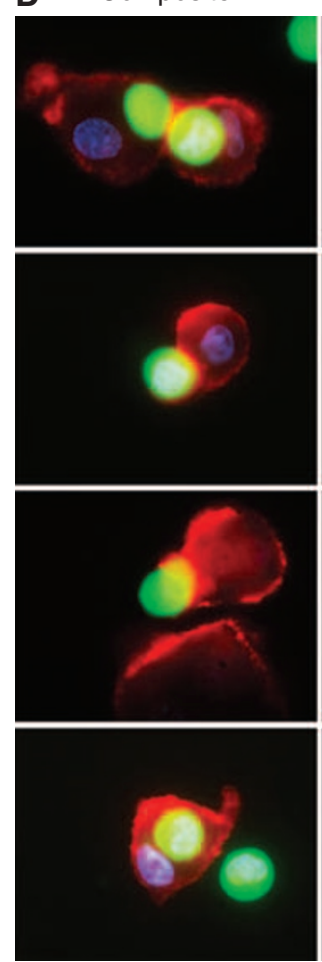

Dapi/nuclei
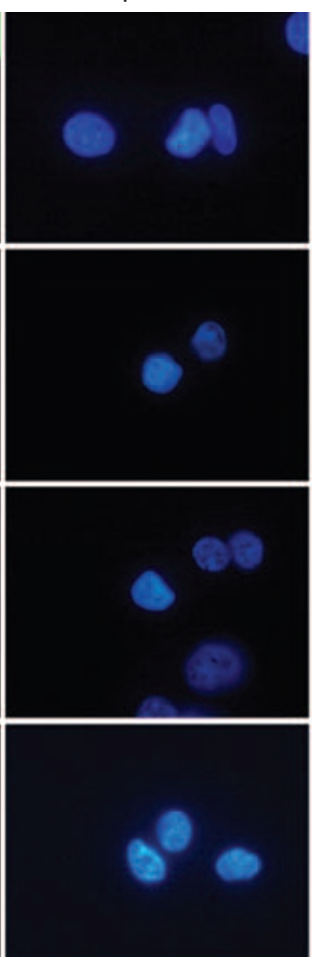

Green/CRC
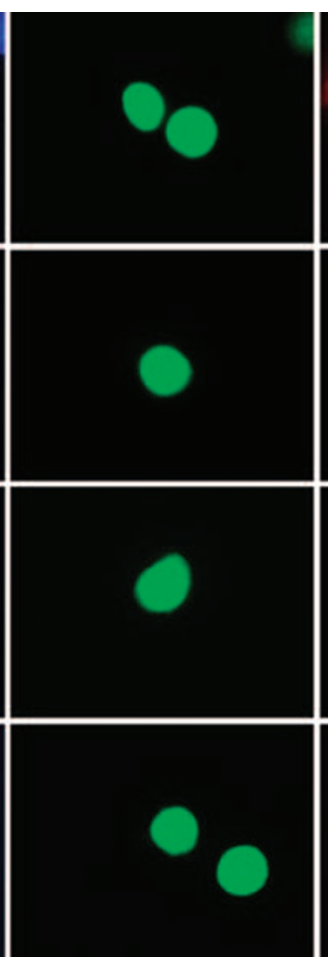

Cy5/macrophage

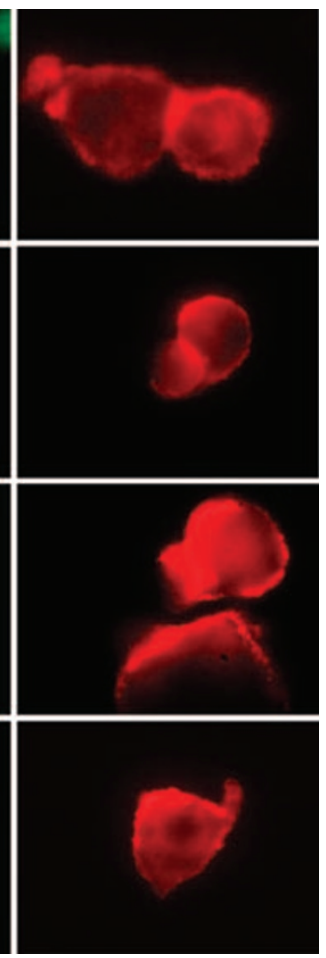

Figure 6 Continued.

Table I Comparison of the ability of different hPRIA3 variants to elicit ADCP using the Ikoniscope

\begin{tabular}{lcrr}
\hline & PMSA control & ghPRIA3 & unPRIA3 \\
\hline Total targets & 1336.00 & 1284.00 & 122.00 \\
Targets engulfed by macrophages & 27.00 & 79.00 & 1428.00 \\
Conjugates between targets and macrophages & 38.00 & 9.50 & 213.00 \\
\% of targets engulfed & 2.02 & 6.15 & 16.00 \\
\% of targets conjugated & 2.84 & 15.65 & 22.92 \\
\% phagocytosis+\% conjugated & 4.87 & 8.12 & 23.04 \\
\% ADCP using FACS & 10.22 & 28.56 \\
\hline
\end{tabular}

The number of target cells that were engulfed by macrophages was counted directly using the lkoniscope. Targets that were conjugated to macrophages were defined as having cell-to-cell membrane contact but no envelopment. Targets and macrophages could readily be identified separately. The percentages of engulfed and conjugated cells are compared with the percentage of targets classified as having undergone ADCP using FACS analysis of the same preparation of cells.

in Figure $6 \mathrm{~B}$ for four different donors. This indicates that, in contrast to ADCC, glycoengineering does not enhance ADCP. The apparent lower level of expression of Fc $\gamma$ RIII (CD16) as compared with Fc $\gamma$ RII (CD32) (see Supplementary Figure S2a) suggests that the density of surface membrane CD16 on macrophages may not be enough for glycoengineering of PR1A3 to enhanced ADCP.

The effects on FACS assayed ADCP of blocking with Fab ${ }_{2}$ fragments each of three classes of $\mathrm{Fc} \gamma \mathrm{Rs}$ receptor are shown in Figure 6C. Blocking Fc $\gamma$ RII (CD32) or Fc $\gamma$ RIII (CD16) reduced $\mathrm{ADCP}$ to some extent, whereas blocking Fc $\gamma \mathrm{RI}$ (CD64) had no effect. This indicates that both CD16 and CD32 are involved in $\mathrm{ADCP}$, whereas previously only CD32 was thought to be mainly involved (Richards et al, 2008). The CD16 antibody (3G8 clone) used for blocking does not, however, distinguish between Fc $\gamma$ RIIIa and Fc $\gamma$ RIIIb. This suggests that the lack of an effect of glycoengineering on ADCP may be due to a lower concentration of Fc $\gamma$ RIIIa than Fc $\gamma$ RIIIb on macrophages, and the fact that the glycoengineering only enhances the binding to $\mathrm{F} \gamma \gamma \mathrm{RIII}$.

For the Ikoniscope-based ADCP assay target, SKCO-1 cells were labelled green with CMFDA and the macrophages red by combining anti-CD11a and anti-CD14 as primary antibodies followed by goat anti-mouse HRP and Tyramide 647 staining. Examples of fluorescent images of macrophages clearly engulfing the target cells, are shown in Figure 6D. In some cases, the macrophages clearly contain two nuclei, one of which is associated with the green stain of a target cell. Using the Ikoniscope it is therefore possible to count, separately, engulfed targets, conjugated targets, free targets and macrophages. Table 1 shows the relative percentage of presumed phagocytosis events seen with the FACS analysis compared with the percentage of confirmed phagocytosis events and percentage of conjugating events seen with the Ikoniscope. Combining engulfed and conjugated targets, as estimated using the Ikoniscope, there is reasonable agreement with the FACS analysis, which cannot distinguish simple attachment from actual engulfment. This suggests that the Ikoniscopebased ADCP assay gives more accurate results than that based on FACS analysis, which is the basis of previous publications reporting ADCP (Munn et al, 1991; Huls et al, 1999; Akewanlop et al, 2001; Lazar et al, 2006; McEarchern et al, 2007). The quantitative data of Table 1 also suggest that the glycoengineered 


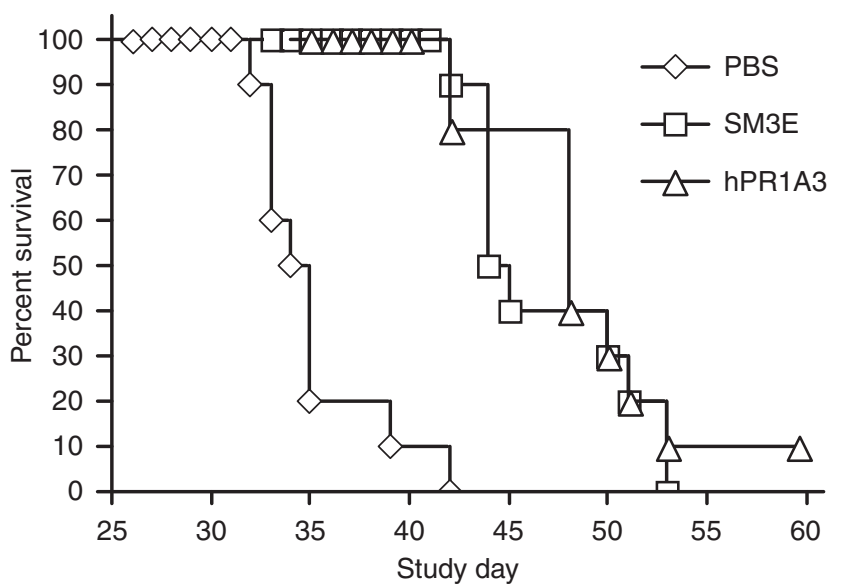

Figure 7 In vivo testing of glycoengineered PRIA3. Survival was measured in SCID/beige mice treated with either glycomodified humanised IgGI PRIA3 $(\triangle)$, glycomodified IgGI SM3E $(\square)$ or vehicle control $(\diamond)$ $(n=10$ in each treatment group). Y-axis represents \% survival and $x$-axis represents number of days after injection of tumour. Both SM3E and PRIA3 increased survival significantly when compared with the vehicle control $(P<0.05)$. There was no significant difference in survival between SM3E and PRIA3 treatments.

antibody may be slightly less effective in eliciting ADCP than the unmodified antibody.

To test its in vivo efficacy, glycoengineered humanised PR1A3 (IgG1 subclass) was used in a murine CRC model consisting of LS174T induced-liver metastasis. The engineered PR1A3 antibody resulted in significantly improved survival of animals when compared with the vehicle PBS control (see Figure 7). A high affinity IgG1 anti-CEA antibody (SM3E) was also used and was found to prolong survival. This antibody is more effective at eliciting in vitro ADCC when compared with PR1A3. However, despite its considerably lower affinity for CEA $\left(K_{\mathrm{d}}, 10 \mathrm{nM} v s 20 \mathrm{pM}\right)$, ghPR1A3 was found to be equally effective at prolonging survival when compared with SM3E. These data show that passive immunisation of glycoengineered humanised IgG1 PR1A3 is effective in prolonging survival in a CEA-positive CRC metastatic tumour model.

\section{DISCUSSION}

Antibody engineering to enhance ADCC can be achieved either by altering the amino acid structure of the $\mathrm{Fc}$ backbone or by modifying the carbohydrate structures at the hinge region (glycoengineering) to improve the binding affinity to $\mathrm{Fc} \gamma$ receptors (Umana et al, 1999; Niwa et al, 2004b; Lazar et al, 2006). Three glycoengineering approaches have been used (i) over expression of the enzyme GntIII in the antibody producing cells, which results in the Fc segment containing an increase in bisected non-fucosylated oligosaccharides, (ii) producing antibody in $\mathrm{CHO}$ cells that lack the transferase enzyme involved in core-fucosylation and (iii) using siRNA to knockdown fucosyl transferase activity. Over expression of GntIII has been used successfully to increase the in vitro ADCC potency of antibodies IGN311 (Lewis Y-specific) and chCE7 (anti-neuroblastoma) (Umana et al, 1999; Schuster et al, 2005). Using this technique, we have shown that the ADCC activity of the humanised IgG1 anti-CEA antibody PR1A3 can be increased more than 10-fold. This effect is seen in both intermediate and high expressing CEA cell lines. The level of enhancement may be pronounced even at low effector:target ratios in intermediate expressing CEA cell lines. This underlines the potency of ghPR1A3, which may be particularly relevant considering that antibody penetration into tumours may limit therapeutic capacity. Therefore, it is of paramount importance to show efficient antibody killing by human effector cells. This ADCC activity is still dependent on CD16 (Fc $\gamma$ RIIIa) on the NK cells, as shown by $\mathrm{Fab}_{2}$ anti-CD16 blocking and enhanced ADCC of ghPR1A3 over uhPR1A3 in the presence of enriched NK cells. The improved ADCC activity of the glycoengineered antibody is achieved without affecting PR1A3's binding activity, leaving it membrane specific, as described earlier (Durbin et al, 1994; Stewart et al, 1999). This is an important property of PR1A3, given the finding that soluble CEA can accumulate in lymph nodes and lead to false positive detection of cancers in lymph nodes when using other anti-CEA antibodies for immunoscintigraphy (Granowska et al, 1989). In contrast to NK cells, neither freshly isolated granulocytes nor monocytes show any significant ADCC activity at comparable antibody concentrations even with high effector: target ratios. The lack of monocyte-based ADCC activity may be due to the low level of CD16 found in our preparations. We have shown, however, using two different assays, that macrophages kill target tumour cells in vitro by ADCP. Both of these mechanisms are therefore likely to have a significant function in in vivo patient responses to naked antibody therapy. Glycoengineering substantially improves antibody PR1A3's NK cell mediated ADCC activity, but apparently has no effect on in vitro macrophage-based ADCP. This suggests that the Fc $\gamma$ RIIIa receptor is not the effective Fc receptor on macrophages for ADCP and opens up the possibility of alternative engineering of antibodies to enhance their ADCP activity (Richards et al, 2008). However, the expression of Fc $\gamma$ Rs on macrophages is dependent on the cytokines in the tumour microenvironment, and so the in vitro assay may not reflect the in vivo situation, and this needs further investigation. The in vivo data presented here show that glycoengineered humanised IgG1 PR1A3 is effective in prolonging survival in a murine CRC metastatic model. This is thought to work by interaction between the Fc segment of the antibody and Fc $\gamma$ RIV, the murine homologue of human Fc $\gamma$ RIIIa. These latter receptors are found on macrophages and granulocytes in mice, emphasising the subtle differences between the mouse and human immune systems. Interestingly, despite the hugely lower affinity for CEA of PR1A3 as compared with SM3E, the improvement in survival was at least as great, if not greater with PR1A3 as with SM3E. This contrasts to the findings in vitro, in which glycoengineered SM3E has a much higher ADCC capacity than PR1A3. The in vivo finding may be explained by the distinctive specificity of PR1A3 for binding to membrane-bound CEA and scavenging of SM3E by shed CEA. Binding to soluble CEA, leading to sequestration of antibodyantigen complexes away from the tumour, is a major obstacle for any potential therapeutic anti-CEA antibody.

The glycoengineered variant antibodies have been shown to have substantially improved binding to the lower affinity Fc $\gamma$ RIIIa receptor polymorphic variants, which have phenylalanine instead of valine at amino acid position 158 (Ferrara et al, 2006). In addition, the carbohydrate residue at Asn-162 of Fc $\gamma$ RIIIa has also been shown to have an important function in the binding of glycoengineered Fc segments, such that its absence leads to greatly attenuated affinity for these antibody variants (Ferrara et al, 2006). As only $10-15 \%$ of patients have the high affinity Fc $\gamma$ RIIIa receptor polymorphic variants, use of the glycoengineered variant antibody should make this therapy accessible to all patients, whatever their genetic constitution with respect to these Fc $\gamma$ RIIIa receptor polymorphic variants (Cartron et al, 2002; Weng and Levy, 2003; Niwa et al, 2004a, b; Schuster et al, 2005).

Earlier studies on macrophage mediated in vitro phagocytosis have relied heavily on FACS analysis using PKH lipid linkers to stain target cells (Munn et al, 1991; Huls et al, 1999; Akewanlop et al, 2001; Lazar et al, 2006; McEarchern et al, 2007; Richards et al, 2008). These linkers can, however, diffuse non-specifically from cell to cell, giving rise to false positive signals and thus limiting 
their use for phagocytosis assays. The use of a cytoplasmic stain, coupled with the Ikoniscope, shows unequivocally that cultured macrophages are able to phagocytose tumour cells in the presence of PR1A3, and enables satisfactory quantitation of the ADCP assay.

The low relative ADCC activity of the murine IgG2a or IgG1 Fc domains on human cells is consistent with the dependence of ADCC on the specificity of the binding of the Fc portion of an antibody to the relevant $\mathrm{Fc}$ receptor (Fc $\gamma \mathrm{RIIIa}$ ) on NK cells. This may, in part, explain the poor results obtained in early oncology trials using naked murine monoclonal antibodies. On the basis of the blocking experiments with $\mathrm{Fab}_{2}$ of $\mathrm{CD} 32$ and CD64, these receptors have little if any role in NK mediated ADCC. However, intact anti-CD32 antibody (clone IV.3, IgG2b), in contrast to the $\mathrm{Fab}_{2}$ fragment (clone 7.3), is as at least as potent as intact antiCD16 in inhibiting both ADCC and antibody-independent killing. This may be explained by low levels of CD32c on NK cells (present in $40 \%$ of donors; Metes et al, 1998) that may lead to self-killing or a secondary cross-linking effect between Fc $\gamma$ Rs.

NK-based ADCC and macrophage-based ADCP are the most likely mechanisms for naked anti-CEA antibody therapy (Munn et al, 1991; Huls et al, 1999; Watanabe et al, 1999; Akewanlop et al, 2001; McEarchern et al, 2007), as there is no obvious basis for a functional blocking effect involving CEA. In addition, macrophages are known to be potent antigen-presenting cells and so, following antibody stimulated engulfment of whole tumour cells, macrophages may digest the engulfed cells and then re-present peptide fragments to T cells. This may then enable the activation of the adaptive immune system against tumour cell products (Adams and Weiner, 2005; Carter, 2006). It is also likely that dendritic cells,

\section{REFERENCES}

Adams GP, Weiner LM (2005) Monoclonal antibody therapy of cancer. Nat Biotechnol 23: 1147-1157

Akewanlop C, Watanabe M, Singh B, Walker M, Kufe DW, Hayes DF (2001) Phagocytosis of breast cancer cells mediated by anti-MUC-1 monoclonal antibody, DF3, and its bispecific antibody. Cancer Res 61: 4061- 4065

Benitez-Ribas D, Adema GJ, Winkels G, Klasen IS, Punt CJ, Figdor CG, de Vries IJ (2006) Plasmacytoid dendritic cells of melanoma patients present exogenous proteins to $\mathrm{CD} 4+\mathrm{T}$ cells after Fc gamma RIImediated uptake. J Exp Med 203: 1629-1635

Blomberg K, Hautala R, Lovgren J, Mukkala VM, Lindqvist C, Akerman K (1996) Time-resolved fluorometric assay for natural killer activity using target cells labelled with a fluorescence enhancing ligand. J Immunol Methods 193: 199-206

Blumenthal RD, Hansen HJ, Goldenberg DM (2008) In vitro and in vivo anticancer efficacy of unconjugated humanized anti-CEA monoclonal antibodies. Br J Cancer 99: 837-838; author reply 839-840

Brodsky FM, Parham P, Barnstable CJ, Crumpton MJ, Bodmer WF (1979) Monoclonal antibodies for analysis of the HLA system. Immunol Rev 47: $3-61$

Carter PJ (2006) Potent antibody therapeutics by design. Nat Rev Immunol 6: $343-357$

Cartron G, Dacheux L, Salles G, Solal-Celigny P, Bardos P, Colombat P, Watier H (2002) Therapeutic activity of humanized anti-CD20 monoclonal antibody and polymorphism in IgG Fc receptor FcgammaRIIIa gene. Blood 99: 754-758

Clynes R (2006) Antitumor antibodies in the treatment of cancer: Fc receptors link opsonic antibody with cellular immunity. Hematol Oncol Clin North Am 20: 585-612

Clynes RA, Towers TL, Presta LG, Ravetch JV (2000) Inhibitory Fc receptors modulate in vivo cytoxicity against tumor targets. Nat Med 6: $443-446$

Conaghan PJ, Ashraf SQ, Tytherleigh MG, Wilding JL, Tchilian E, Bicknell D, Mortensen NJ, Bodmer WF (2008) Targeted killing of colorectal cancer cell lines by a humanised IgG1 monoclonal antibody that binds to membrane-bound carcinoembryonic antigen. Br J Cancer 98: $1217-1225$ which are super antigen presenters and express Fc $\gamma$ Rs, are stimulated by antibodies to engulf target cells, which would significantly enhance their ability to present tumour antigens to the adaptive immune system (Kalergis and Ravetch, 2002; BenitezRibas et al, 2006; Melief, 2008). Glycoengineering and other modifications of antibodies to enhance their immune effector functions appear, therefore, to be a most effective way to improve the efficacy of naked antibody therapy by a variety of mechanisms.

\section{ACKNOWLEDGEMENTS}

We thank Sylvia Bartlett, David Bicknell, Fernando Martinez Estrada and Ying Liu for technical help during the project. SQA was funded by a Bobby Moore Fellowship, CRUK and general support was provided by a CRUK programme grant. We also thank Ikonisys, New Haven, Connecticut, for their support of Triantafyllia Ntouroupi and the provision of the Ikonoscope.

\section{Conflict of interest}

PU, EM and PB are employed by Glycart, Roche. Glycart have provided CIL with antibodies and a grant partly covering laboratory expenses. There is a commercial agreement between CIL (WFB) and Glycart, Roche, for the development of PR1A3.

Supplementary Information accompanies the paper on British Journal of Cancer website (http://www.nature.com/bjc)

Cunningham D, Humblet Y, Siena S, Khayat D, Bleiberg H, Santoro A, Bets D, Mueser M, Harstrick A, Verslype C, Chau I, Van Cutsem E (2004) Cetuximab monotherapy and cetuximab plus irinotecan in irinotecan-refractory metastatic colorectal cancer. $N$ Engl J Med 351: $337-345$

Dhodapkar KM, Kaufman JL, Ehlers M, Banerjee DK, Bonvini E, Koenig S, Steinman RM, Ravetch JV, Dhodapkar MV (2005) Selective blockade of inhibitory Fcgamma receptor enables human dendritic cell maturation with IL-12p70 production and immunity to antibody-coated tumor cells. Proc Natl Acad Sci USA 102: 2910-2915

Durbin H, Bodmer WF (1987) A sensitive micro-immunoassay using betagalactosidase/anti-beta-galactosidase complexes. J Immunol Methods 97: $19-27$

Durbin H, Young S, Stewart LM, Wrba F, Rowan AJ, Snary D, Bodmer WF (1994) An epitope on carcinoembryonic antigen defined by the clinically relevant antibody PR1A3. Proc Natl Acad Sci USA 91: 4313-4317

Ferrara C, Stuart F, Sondermann P, Brunker P, Umana P (2006) The carbohydrate at FcgammaRIIIa Asn-162. An element required for high affinity binding to non-fucosylated IgG glycoforms. J Biol Chem 281: $5032-5036$

Goldberg RM (2005) Cetuximab. Nat Rev Drug Discov (Suppl): S10-S11

Goldenberg DM (2002) Targeted therapy of cancer with radiolabeled antibodies. J Nucl Med 43: 693-713

Graff CP, Chester K, Begent R, Wittrup KD (2004) Directed evolution of an anti-carcinoembryonic antigen $\mathrm{scFv}$ with a 4-day monovalent dissociation half-time at 37 degrees C. Protein Eng Des Sel 17: 293-304

Granowska M (1993) Radioimmunoscintigraphy with technetium-99m labelled monoclonal antibody, 1A3, in colorectal cancer. Eur J Nucl Med 20: 1128

Granowska M, Jass JR, Britton KE, Northover JM (1989) A prospective study of the use of 111 In-labelled monoclonal antibody against carcinoembryonic antigen in colorectal cancer and of some biological factors affecting its uptake. Int J Colorectal Dis 4: 97-108

Huls G, Heijnen IA, Cuomo E, van der Linden J, Boel E, van de Winkel JG, Logtenberg T (1999) Antitumor immune effector mechanisms recruited by phage display-derived fully human IgG1 and IgA1 monoclonal antibodies. Cancer Res 59: 5778-5784 
Jones PT, Dear PH, Foote J, Neuberger MS, Winter G (1986) Replacing the complementarity-determining regions in a human antibody with those from a mouse. Nature 321: $522-525$

Kalergis AM, Ravetch JV (2002) Inducing tumor immunity through the selective engagement of activating Fcgamma receptors on dendritic cells. J Exp Med 195: 1653-1659

Karagiannis SN, Bracher MG, Hunt J, McCloskey N, Beavil RL, Beavil AJ, Fear DJ, Thompson RG, East N, Burke F, Moore RJ, Dombrowicz DD, Balkwill FR, Gould HJ (2007) IgE-antibody-dependent immunotherapy of solid tumors: cytotoxic and phagocytic mechanisms of eradication of ovarian cancer cells. J Immunol 179: 2832-2843

Lazar GA, Dang W, Karki S, Vafa O, Peng JS, Hyun L, Chan C, Chung HS, Eivazi A, Yoder SC, Vielmetter J, Carmichael DF, Hayes RJ, Dahiyat BI (2006) Engineered antibody Fc variants with enhanced effector function. Proc Natl Acad Sci USA 103: 4005-4010

Liersch T, Meller J, Kulle B, Behr TM, Markus P, Langer C, Ghadimi BM, Wegener WA, Kovacs J, Horak ID, Becker H, Goldenberg DM (2005) Phase II trial of carcinoembryonic antigen radioimmunotherapy with 131I-labetuzumab after salvage resection of colorectal metastases in the liver: five-year safety and efficacy results. J Clin Oncol 23: $6763-6770$

McEarchern JA, Oflazoglu E, Francisco L, McDonagh CF, Gordon KA, Stone I, Klussman K, Turcott E, van Rooijen N, Carter P, Grewal IS, Wah AF, Law CL (2007) Engineered anti-CD70 antibody with multiple effector functions exhibits in vitro and in vivo antitumor activities. Blood 109: $1185-1192$

McLaughlin P, Grillo-Lopez AJ, Link BK, Levy R, Czuczman MS, Williams ME, Heyman MR, Bence-Bruckler I, White CA, Cabanillas F, Jain V, Ho AD, Lister J, Wey K, Shen D, Dallaire BK (1998) Rituximab chimeric anti-CD20 monoclonal antibody therapy for relapsed indolent lymphoma: half of patients respond to a four-dose treatment program. J Clin Oncol 16: $2825-2833$

Melief CJ (2008) Cancer immunotherapy by dendritic cells. Immunity 29: $372-383$

Metes D, Ernst LK, Chambers WH, Sulica A, Herberman RB, Morel PA (1998) Expression of functional CD32 molecules on human NK cells is determined by an allelic polymorphism of the FcgammaRIIC gene. Blood 91: $2369-2380$

Munn DH, McBride M, Cheung NK (1991) Role of low-affinity Fc receptors in antibody-dependent tumor cell phagocytosis by human monocytederived macrophages. Cancer Res 51: 1117-1123

Musolino A, Naldi N, Bortesi B, Pezzuolo D, Capelletti M, Missale G, Laccabue D, Zerbini A, Camisa R, Bisagni G, Neri TM, Ardizzoni A (2008) Immunoglobulin $G$ fragment $C$ receptor polymorphisms and clinical efficacy of trastuzumab-based therapy in patients with HER-2/ neu-positive metastatic breast cancer. J Clin Oncol 26: 1789-1796

Niwa R, Hatanaka S, Shoji-Hosaka E, Sakurada M, Kobayashi Y, Uehara A, Yokoi H, Nakamura K, Shitara K (2004a) Enhancement of the antibodydependent cellular cytotoxicity of low-fucose IgG1 Is independent of FcgammaRIIIa functional polymorphism. Clin Cancer Res 10: 6248-6255

Niwa R, Shoji-Hosaka E, Sakurada M, Shinkawa T, Uchida K, Nakamura K, Matsushima K, Ueda R, Hanai N, Shitara K (2004b) Defucosylated chimeric anti-CC chemokine receptor 4 IgG1 with enhanced antibodydependent cellular cytotoxicity shows potent therapeutic activity to T-cell leukemia and lymphoma. Cancer Res 64: 2127-2133
Ntouroupi TG, Ashraf SQ, McGregor SB, Turney BW, Seppo A, Kim Y, Wang X, Kilpatrick MW, Tsipouras P, Tafas T, Bodmer WF (2008) Detection of circulating tumour cells in peripheral blood with an automated scanning fluorescence microscope. Br J Cancer 99: 789-795

Olszewski AJ, Grossbard ML (2004) Empowering targeted therapy: lessons from rituximab. Sci STKE 2004: pe30

Reichert JM, Valge-Archer VE (2007) Development trends for monoclonal antibody cancer therapeutics. Nat Rev Drug Discov 6: 349-356

Richards JO, Karki S, Lazar GA, Chen H, Dang W, Desjarlais JR (2008) Optimization of antibody binding to FcgammaRIIa enhances macrophage phagocytosis of tumor cells. Mol Cancer Ther 7: 2517-2527

Richman PI, Bodmer WF (1987) Monoclonal antibodies to human colorectal epithelium: markers for differentiation and tumour characterization. Int J Cancer 39: 317-328

Roda JM, Parihar R, Lehman A, Mani A, Tridandapani S, Carson III WE (2006) Interleukin-21 enhances NK cell activation in response to antibody-coated targets. J Immunol 177: 120 - 129

Saltz L, Easley C, Kirkpatrick P (2006) Panitumumab. Nat Rev Drug Discov 5: $987-988$

Schmitz M, Zhao S, Schakel K, Bornhauser M, Ockert D, Rieber EP (2002) Native human blood dendritic cells as potent effectors in antibodydependent cellular cytotoxicity. Blood 100: 1502-1504

Schuster M, Umana P, Ferrara C, Brunker P, Gerdes C, Waxenecker G, Wiederkum S, Schwager C, Loibner H, Himmler G, Mudde GC (2005) Improved effector functions of a therapeutic monoclonal Lewis Y-specific antibody by glycoform engineering. Cancer Res 65: $7934-7941$

Sharkey RM, Goldenberg DM (2005) Perspectives on cancer therapy with radiolabeled monoclonal antibodies. J Nucl Med 46(Suppl 1): 115S-127S

Stewart LM, Young S, Watson G, Mather SJ, Bates PA, Band HA, Wilkinson RW, Ross EL, Snary D (1999) Humanisation and characterisation of PR1A3, a monoclonal antibody specific for cell-bound carcinoembryonic antigen. Cancer Immunol Immunother 47: 299-306

Umana P, Jean-Mairet J, Moudry R, Amstutz H, Bailey JE (1999) Engineered glycoforms of an antineuroblastoma IgG1 with optimized antibody-dependent cellular cytotoxic activity. Nat Biotechnol 17: $176-180$

Watanabe M, Wallace PK, Keler T, Deo YM, Akewanlop C, Hayes DF (1999) Antibody dependent cellular phagocytosis (ADCP) and antibody dependent cellular cytotoxicity (ADCC) of breast cancer cells mediated by bispecific antibody, MDX-210. Breast Cancer Res Treat 53: 199-207

Weng WK, Levy R (2003) Two immunoglobulin G fragment C receptor polymorphisms independently predict response to rituximab in patients with follicular lymphoma. J Clin Oncol 21: 3940-3947

Wong JY, Chu DZ, Williams LE, Yamauchi DM, Ikle DN, Kwok CS, Liu A, Wilczynski S, Colcher D, Yazaki PJ, Shively JE, Wu AM, Raubitschek AA (2004) Pilot trial evaluating an 123I-labeled 80-kilodalton engineered anticarcinoembryonic antigen antibody fragment (cT84.66 minibody) in patients with colorectal cancer. Clin Cancer Res 10: 5014-5021

Zhang W, Gordon M, Schultheis AM, Yang DY, Nagashima F, Azuma M, Chang HM, Borucka E, Lurje G, Sherrod AE, Iqbal S, Groshen S, Lenz H] (2007) FCGR2A and FCGR3A polymorphisms associated with clinical outcome of epidermal growth factor receptor expressing metastatic colorectal cancer patients treated with single-agent cetuximab. J Clin Oncol 25: $3712-3718$ 